\section{Expression and Localization of VIP in Different Segments of Pigeon Intestine}

\author{
Fei Wang ${ }^{1}$, Xianlai Zhang ${ }^{1}$, Youbao Zhong ${ }^{2}$, Xiaoen Tang ${ }^{3}$, Xiaofen Hu${ }^{1}$, \\ ShanShan Yang', Shengwei Zhong ${ }^{1}$, Zuohong Zhou', Jin Liu', Xu Yuan' \\ and Yong $\mathrm{Li}^{1 *}$
}

${ }^{1}$ College of Animal Science and Technology, Jiangxi Agricultural University, No. 1101

Zhimin Avenue, Economic and Technological Development District, Nanchang 330045, Jiangxi, P. R. China

${ }^{2}$ Technology Center of Experimental Animal, Jiangxi University of Traditional Chinese Medicine, No. 1688 Meiling Avenue, Wanli District, Nanchang 330004, Jiangxi, P. R. China

${ }^{3}$ Fuzhou Husbandry Breeding Farm, Linchuan 344000, Jiangxi, P. R. China
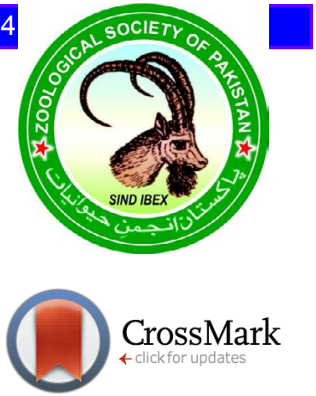

\begin{abstract}
A B S T R A C T
In order to further investigate the structural characteristic of pigeon intestine, the microstructure of each part of intestine was analyzed by HE staining, and its vasoactive intestinal peptide (VIP) was detected by immunohistochemistry staining and RT-qPCR. In present results, the intestinal mucosa epithelium is a single layer of columnar epithelium, other structures are relatively complete, and the intestinal villi and glands are distinct in each part of intestine. The localization of VIP is extensive in the intestinal wall, but most typical in the lamina propria and muscular layer; VIP in mucosal epithelium is mainly distributed within goblet cells. The distribution of VIP is stronger in the duodenum than in other parts, followed by the rectum, ileum, and jejunum. The lamina propria, muscular layer and serosa always contain VIP nerve fibers with deep staining. Unexpectedly, the results of RT-qPCR showed that the expression level is consistent with that of immunohistochemical detection. It is indicated VIP probably participate in the functional regulation of pigeon intestine as a key role and mediate the neuroendocrine and mucosal immune system as an information molecule due to the high expression of VIP. It will provide the basis for clarifying the biological function of VIP in pigeons.
\end{abstract}

\author{
Article Information \\ Received 08 February 2020 \\ Revised 09 March 2020 \\ Accepted 13 April 2020 \\ Available online 14 September 2020 \\ Authors' Contribution \\ FW, $X Z$ and $Y L$ conceived and \\ conducted the study. YZ, XT, XH, \\ SY, SZ, ZZ, JL and XY collected and \\ analyzed the data. YL and FW wrote \\ and revised the manuscript. \\ Key words \\ Pigeon, Intestine, Vasoactive intestinal \\ peptide, Expression and localization, \\ Microstructure
}

\section{INTRODUCTION}

I $\mathrm{t}$ is well known that pigeon is a kind of fowl commonly raised in China. Its meat is popularly considered as a tender, high-protein and low-fat poultry meat. In recent years, the market demand for pigeons has gradually increased. However, some bad managements, for example, wet litter, bad ventilation, high density of birds, improper coccidiostat consumption and contaminated feeders, exaggerate intestinal parasite problems (Ruff, 1993). The parasitism often brings about severe effects on birds including malnutrition, retarded growth, low egg production, susceptibility to other infections, and death in young birds (Radfar et al., 2012), these similar digestive diseases account for a large part of pigeon's disease, so as to seriously threatens pigeon's normal breeding. The intestinal mucosal immune structure belongs to an inseparable and important part of body's immune system

\footnotetext{
* Corresponding author: liyong2912@163.com 0030-9923/2020/0006-2299 \$ 9.00/0 Copyright 2020 Zoological Society of Pakistan
}

as the first defense line. When the intestinal mucosal barrier is destroyed, intestinal microbes and toxins easily enter the blood circulation to result in inflammation of the body or failure of organ function (Zhou et al., 2017). Studies have shown that the mucosal immunity and neuroendocrine systems are closely linked by common biological language. For example, diffuse neuroendocrine cells in lymphoid tissues of the sacculus rotundus may participate in and regulate the local intestinal mucosal immune response in rabbits (She et al., 2008). Considering that the impairment on mucosal immunity of intestine significantly increases the risk of acute and chronic diseases (Tremaroli and Backhed, 2012; Samuelson et al., 2015), it is of great importance to understand the mechanism on regulating intestinal immune responses. Therefore, study on the intestinal structure is beneficial to make clear the detailed characteristics of the digestive system in pigeons, it will provides a theoretical basis for treatment on pigeon's digestive diseases.

Vasoactive intestinal peptide (VIP), known as vasopressin, was firstly isolated from the small intestine of pig. VIP consists of 28 amino acids and belongs to a member of the secretin/glucagon family (Said and 
Mutt, 1970). It acts as both a gastrointestinal hormone and a neuropeptide in the body. As an effective antiinflammatory factor, VIP has the effect of inhibiting $\mathrm{T}$ cell proliferation (Gonzalez-Rey et al., 2007). In addition, VIP inhibits the production of inflammatory cytokines and chemokines by macrophages, microglia and dendritic cells via its receptors VPAC 1 and VPAC 2 (Gonzalez-Rey et al., 2007). VIP is also a signaling molecule between the nervous and immune system, and plays a role in immunity, especially in local mucosal immunity (Delgado and Ganea, 2013). However, more studies have still focused on the function of VIP related with intestine, intestinal inflammation is inhibited by cross-talk between Vagus Nerve Released Acetylcholine and VIP (Van der Zanden et $a l ., 2010)$. VIP is responsible for the induction of IGN as a local neuromodulator released by intrinsic enteric neurons (De Vadder et al., 2015). VPAC1 protein levels are higher in the mouse colon, followed by the ileum and jejunum (Jayawardena et al., 2017). VIP regulates ileal goblet cell production in mice (Schwerdtfeger and Tobet, 2020). Due to few reports on VIP in pigeon's intestine, the present study was aim to further improve and enrich the histological theory. It is helpful to significantly clarify its innervations and function in intestine and comprehend the relationship between the mucosal immune and neuroendocrine system.

\section{MATERIALS AND METHODS}

\section{Experimental animals}

10 healthy pigeons ( 26 days old, weighing $500 \pm 5 \mathrm{~g}$, half male and half female) were purchased on March 4, 2019, and kept in Animal Anatomy Laboratory of Jiangxi Agricultural University for one day of fasting. On the next day, after pigeons were anesthetized and dissected, the duodenum, jejunum, ileum and rectum were taken immediately from its intestine. Some of these tissues were respectively fixed in Bouin's or 4\% paraformaldehyde solution for 24 to $72 \mathrm{~h}$, other tissues was quickly added into liquid nitrogen, and then stored in refrigerator at $-80^{\circ} \mathrm{C}$. All of the procedures were performed in accordance with the Ethics Committee and Guidelines of Animal Experiments of the institute throughout the experiment.

\section{Tissue treatment}

The above fixed tissues were rinsed with running water for $5-10 \mathrm{~h}$, then dehydrated in $70 \%, 80 \%, 90 \%, 95 \%$, $100 \%$ ethanol by LEICA ASP200S automatic dehydrator, transparentized in xylene for 3 times, and dipped in wax for $3-4 \mathrm{~h}$. $4 \mu \mathrm{m}$ continuous sections were cut with LEICA semi-automatic paraffin slicer. Half of these sections were processed for hematoxylin-eosin staining and the other for immunohistochemical staining.
Hematoxylin-eosin staining was done according to Zhong et al. (2018). For immunohistochemical staining procedure of Zhong et al.(2017) was followed after dewaxing, each tissue section was added endogenous peroxidase blocking solution and then incubated at $37^{\circ} \mathrm{C}$ for $15 \mathrm{~min}$. The antigen was repaired at $98^{\circ} \mathrm{C}$ for $12 \mathrm{~min}$ and then incubated with goat serum in a $37^{\circ} \mathrm{C}$ oven for 20 min. Rabbit anti-VIP polyclonal antibody was added dropwise on sections and then incubated at $4{ }^{\circ} \mathrm{C}$ overnight. After the primary antibody was ligated, the sections were incubated with biotin-labeled goat anti-rabbit secondary antibody for $30 \mathrm{~min}$ at $37^{\circ} \mathrm{C}$, combined with peroxidaselabeled streptavidin for $10 \mathrm{~min}$ at room temperature, and visualized by DAB coloring agent for 1-5 min. Then the sections were counterstained in hematoxylin solution for $2 \mathrm{~min}$, processed in $1 \mathrm{ml} / \mathrm{L}$ hydrochloric acid alcohol differentiation and blue-back fluid, and rinsed with distilled water. Lastly, the sections were dehydrated, transparentized, and mounted with neutral balsam and cover slips, subsequently, were analyzed and photographed under light microscope. By contrast, the primary antibody was replaced with $0.01 \mathrm{~mol} / \mathrm{L}$ PBS solution in the control group, but the remaining steps were treated the same as above.

\section{RNA extraction and $c D N A$ synthesis}

RNA was extracted from each tissue of pigeon according to the Trizol method, and the RNA concentration and OD value were determined by an ultraviolet spectrophotometer. The desired cDNAs were synthesized according to the reverse transcription kit and placed in refrigerator at $-20^{\circ} \mathrm{C}$.

\section{Real-time quantitative PCR detection}

Real-time quantitative PCR was run to detect the expression of VIP in different intestinal tissues. The cDNA of each tissue was used as a template, and GAPDH gene was used as an internal reference. The reaction system is $20 \mu$ as following: $2 \times \mathrm{qPCR}$ Mix $10 \mu \mathrm{l}, 10 \mu \mathrm{mol} / \mathrm{L}$ upstream and downstream primers $0.4 \mu \mathrm{l}$ (Table I), cDNA $2 \mu 1$, Nuclease-free water $7.2 \mu \mathrm{l}$. The PCR reaction conditions were performed by the pre-denaturation phase of template at $94{ }^{\circ} \mathrm{C}$ for $30 \mathrm{sec}$, and a total of 42 cycles for the template amplification phase at $94^{\circ} \mathrm{C}$ for $5 \mathrm{sec}$ and $62^{\circ} \mathrm{C}$ for $30 \mathrm{sec}$, lastly slowly increasing the temperature by $0.5^{\circ} \mathrm{C}$ every 10 sec from $55^{\circ} \mathrm{C}$ to $95^{\circ} \mathrm{C}$. The results were calculated by the $2^{-\triangle \triangle \mathrm{Ct}}$ method.

\section{RESULTS}

Histological structure of pigeon intestine

According to the histological analysis, the intestinal 
wall of pigeon is clearly divided into mucosal layer, submucosa, muscular layer and serosal layer. The mucosal layer is further divided into epithelial layer, lamina propria and mucosal muscle layer (Fig. 1). The villi of mucosa are obvious in each segment of the intestine, and the epithelium of the intestinal villi is recessed into the lamina propria to form a crypt; the lamina propria contains scattered and isolated lymph nodules. The duodenum not only has the largest number of dense intestinal villi with long and straight leafy shape, and also has numerous intestinal glands (Fig. 1A). In the jejunum (Fig. 1B), the mucosal layer has a dense number of fluffs with finger-like. The ileum has fewer fluffs than the duodenum and jejunum and is tapered to the submucosal layer with lymph nodules (Fig. 1C). Intestinal velvet hair and many intestinal glands were found in pigeons, but the intestinal villi and glands in the small intestine are more than those in the large intestine (Fig. 1). The rectal villi are longer than that of ileum, and the serosal layer contains lymph nodules.

Table I. The primer sequences for real-time PCR and predicted product length.

\begin{tabular}{llll}
\hline Gene & Primer sequence $\left(\mathbf{5}^{\prime} \rightarrow \mathbf{3}^{\prime}\right)$ & $\begin{array}{l}\text { Product } \\
\text { length }\end{array}$ & Tm \\
\hline VIP & $\begin{array}{l}\text { TTGGGAAACAGAATGCC } \\
\text { GAAGACAGCGTCAGAGTG }\end{array}$ & 183 & 62 \\
GAPDH & $\begin{array}{l}\text { CCCAGAACATTATTCCAGC } \\
\text { CAGCACCCGCATCAAAG }\end{array}$ & 291 & 62 \\
\hline
\end{tabular}

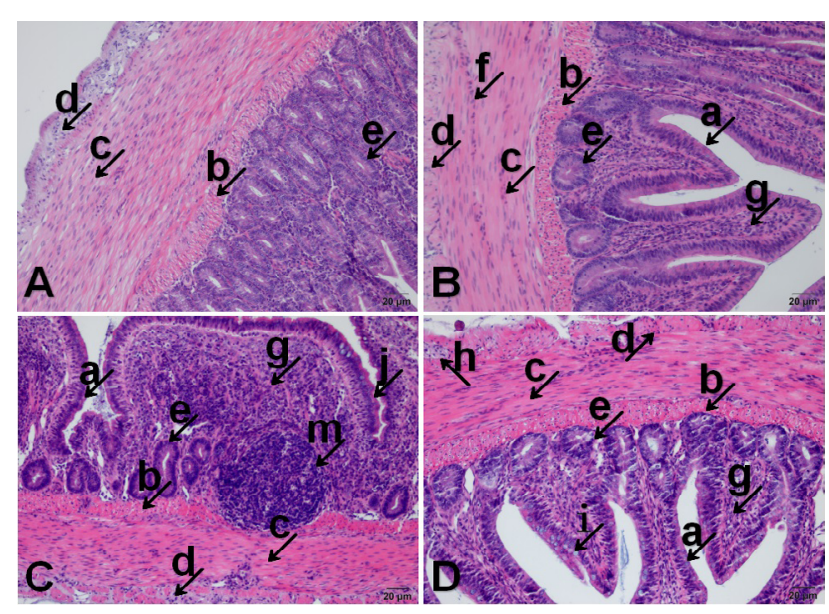

Fig. 1. The histological structure of pigeon intestine (HE staining: 200×). A, duodenum; B, jejunum; C, ileum; D, rectum. Note: a, mucosal epithelium; $b$, mucous muscle layer; c, muscular layer; d, serosa; e, gland; f, nerve fiber; $g$, lamina propria; h, lymph nodule; i, goblet cells; $\mathrm{j}$, striatum; $\mathrm{k}$, columnar cells; 1 , central chyle tube; $\mathrm{m}$, Isolated lymph nodule; n, lymphocyte.
Meanwhile, there are goblet cells between the columnar cells of mucosa in pigeon, and the number of goblet cells is small in the small intestine but is large in the large intestine. The nucleus of the columnar cells are elliptical and located at their base; the goblet cells are lightly stained with elliptical nucleus too (Fig. 2). The duodenal glands are visible in the submucosa and consist of a large number of columnar cells and a small number of goblet cells (Fig. 2). Isolated lymph nodules are distributed in the lamina propria of small intestine, and the inner edge of the intestinal villi can be clearly seen. While the striate edge appears, there is a central chyle tube in the intestinal villi (Fig. 2B).
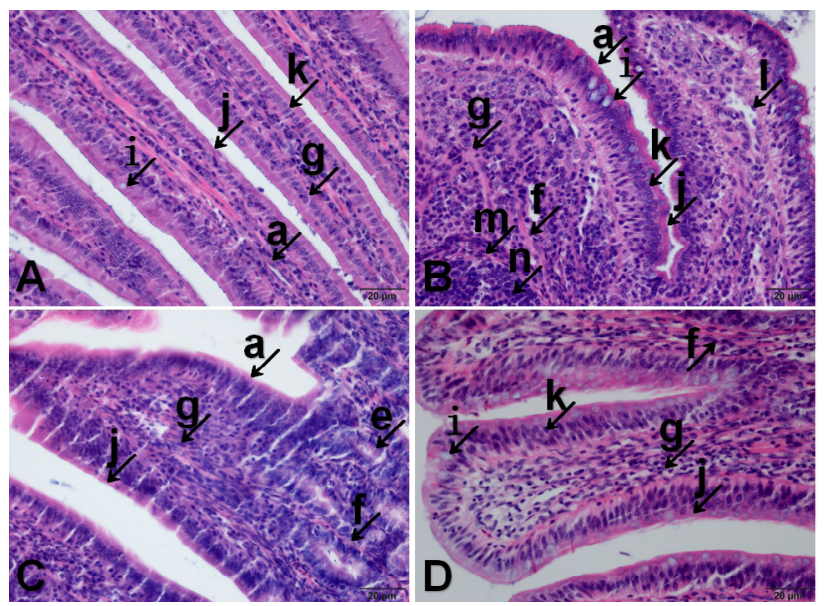

Fig. 2. The fluff structure of pigeon intestine (HE staining: $400 \times$ ). A, duodenum-fluff; B, jejunum-fluff; C, ileum-fluff; $D$, rectum-fluff. Note: a, mucosal epithelium; $b$, mucous muscle layer; c, muscular layer; $d$, serosa; e, gland; f, nerve fiber; g, lamina propria; h, lymph nodule; i, goblet cells; $\mathrm{j}$, striatum; $\mathrm{k}$, columnar cells; 1 , central chyle tube; $\mathrm{m}$, isolated lymph nodule; n, lymphocyte.

\section{Distribution of VIP in the small intestine}

In the sections stained by immunohistochemical method, the positive cells were brownish yellow. According to the depth of staining, it can be divided into weak positive (light color + ), positive (medium color ++ ) and strong positive (deep color +++ ). VIP expression is found in the intestinal segments of pigeons (duodenum, jejunum, ileum and rectum). VIP is widely distributed in the mucosal epithelium and lamina propria, muscular layer and adventitia.

VIP-positive cells in the duodenal mucosal epithelium are large round or oval individuals (Fig. 3A); positive staining is mainly distributed in the lamina propria and muscles. In the layer, the lamina propria showed visible positive nerve fibers, and there are few VIP-positive cells during the period; more positive cells are found 
between the epithelial cells of the intestinal glands, and their morphology is mainly circular or elliptical (Fig. 3E); positive nerve fibers are visible in mucosal muscles, and its staining is deep; positive and deep-stained positive nerve fibers are seen in the muscular layer and the outer membrane (Fig. 3A). A small number of VIP weakly positive cells are observed in the jejunal epithelium and are small round or elliptical. Some diffuse VIP is distributed in the lamina propria, and VIP-positive nerve fibers can be diffusely seen longitudinally along the long axis of the villi (Fig. 3F). The muscular layer has developed positive nerve fibers, which are beaded or thin-lined around this layer; a small number of VIP-positive cells are visible in the intestine with oval or round shape. The outer membrane shows weakly or moderately stained positive nerve fibers, there are more positive cells in the lymph nodules (Fig. $3 \mathrm{~B})$. There are more positive cells in the mucosa of its ileum; the deep-stained positive nerve fibers can be seen in the lamina propria, which are thin-line or strip-like, longitudinally distributed along the long axis of the villi (Fig. 3G), and there are scattered deep-stained VIP-positive cells between the fibers. These cells are small in size and look elliptical or irregular. There are a large number of VIPpositive cells in the lymph nodules with irregular shape; medium positive nerve fibers are observed in the mucosal muscles and muscular layers, and the deep-stained positive nerve fibers appear in the outer membrane (Fig. 3C). There are many positive cells in the rectum, which are round and stained deeply. The deep-stained positive nerve fibers can be seen in the lamina propria with strip-like, and there are sporadic VIP positive cells between the fibers, which are oval or irregular (Fig. 3H). The muscular layer has positive nerve fibers and is beaded; most of VIP positive cells in the intestine are round or elliptical. The deeper stained positive fibers are also visible in the outer membrane (Fig. 3D).

The above results indicate that VIP is extensively distributed in the intestinal tissue of pigeons, involving the epithelial and lamina propria, the muscular layer and the adventitia of mucosa, but those are more typical in the lamina propria and the muscular layer; its duodenum and rectum have VIP-positive cells with the deepest staining, and are stronger than other intestinal segments, followed by the ileum and the jejunum along with relatively less expression.

\section{Expression analysis of VIP in different segments of intestine}

According to the results of real-time quantitative PCR (Fig. 4), it can be found that VIP gene expresses in the intestine of pigeon, the expression level is relatively high in the duodenum, followed by the rectum and the ileum, and the lowest expression level exists in the jejunum.

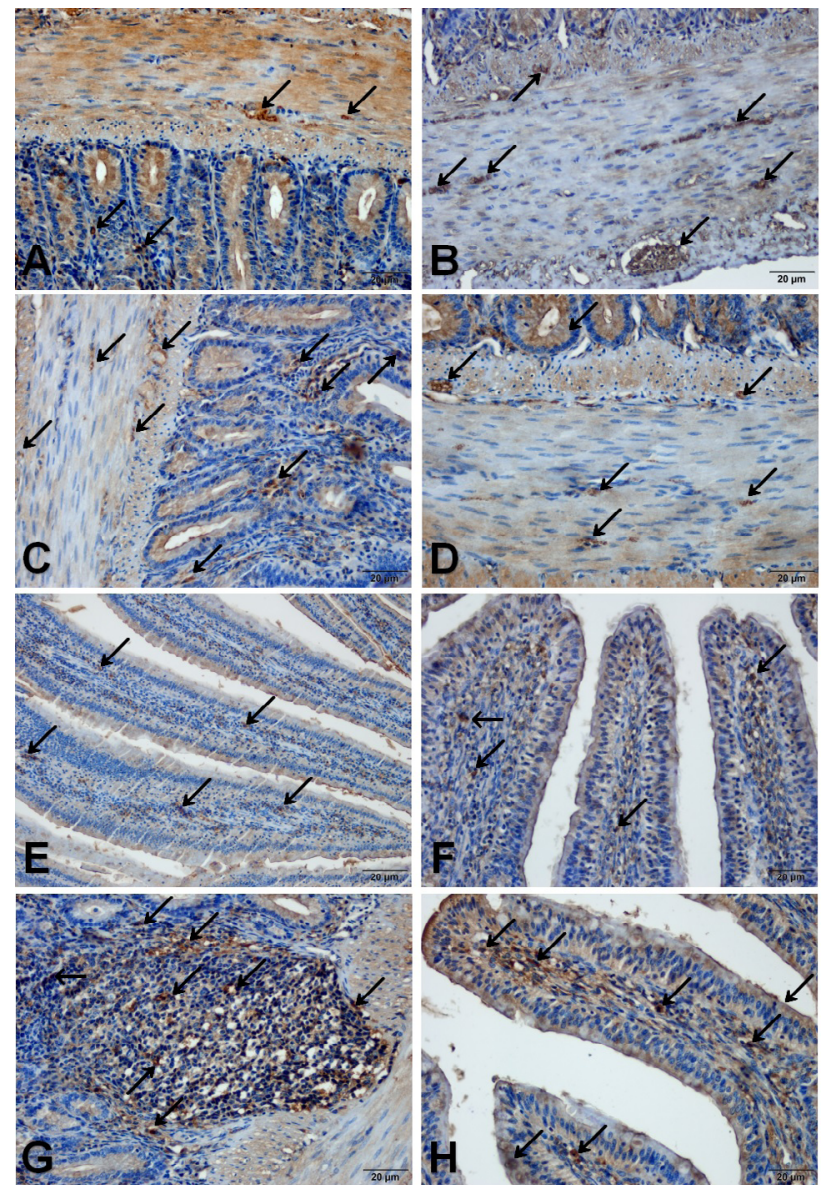

Fig. 3. Immunohistochemical examination of VIP in various segments of pigeon's intestine (Immunohistochemical staining: 400×). A, duodenum; B, jejunum; C, ileum; D, Rectum; E, Duodenum-villi; F, Jejunum-fluff; G, Ileum-fluff; $\mathrm{H}$, rectum-fluff. Black arrows pointing VIP positive cells.

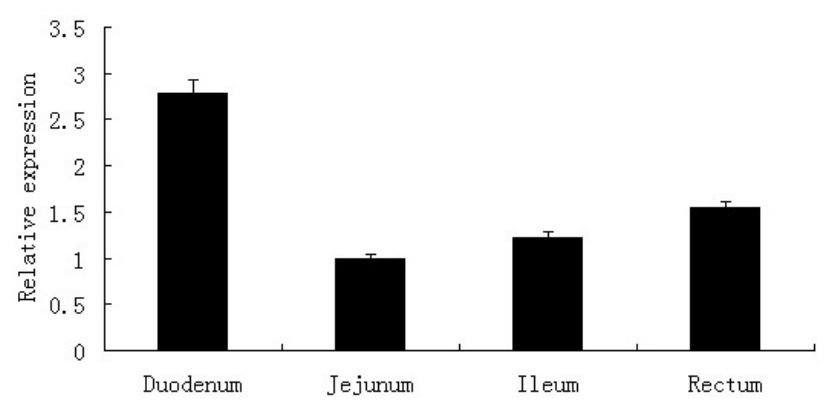

Fig. 4. Expression of VIP in various segments of pigeon's intestine. 


\section{DISCUSSION}

\section{Intestinal histological structure supports its function}

Generally, the intestine structure of pigeon is similar with that of other birds, which has no central chyle tube in the villi, but a large number of duodenal glands exist in pigeon. The goblet cells between the epithelial cells gradually increase from front to back, especially in the rectum, which differs from other birds' structure. According to the study on various breeds of beef cattle, the more developed the small intestinal villi are, stronger would be their digestion and absorption capacity (Wang et al., 2010). It is further indicated that the digestion and absorption of nutrients are mainly concentrated in the anterior segment of small intestine. The intestinal glands are developed in mucosa (Liu et al., 1985); the highly developed intestinal glands can secrete more intestinal fluid containing digestive enzymes, which are more conducive to food digestion. Studies have shown that three segments of small intestine have different special absorption functions, the duodenum mainly absorbs water-soluble cellulose and fatty acids, the jejunum mainly absorbs glucose and $\mathrm{Na}^{+}$, etc., and the ileum mainly absorbs vitamin $\mathrm{B}_{12}$ and bile salts, etc. (Turner and Turner, 2010). On the one hand, the small intestinal glands in pigeon are developed so as to secrete more digestive juice, which helps the food to be further digested and absorbed. On the other hand, small intestinal gland cells, even goblet cells in the jejunum can secrete some active substances to enhance intestinal immune function. Gao (2009) found that the lymphoid tissue of large intestine mucosa in the bactrian camel can participate in and regulate the local immune function of the intestine through specific immune mechanisms. The mucosal layer of small intestine in pigeon has a large number of lymphocytes, especially the isolated lymph nodules in ileum, and the developed lymphoid tissue can enhance the immunity of pigeon intestine.

\section{Significance of VIP-positive cell in the intestinal wall}

The intestinal tract is the main site of avian mucosal immunity, exploration for avian innervation of intestine is an important aspect for comprehending its neuroendocrine and immune system. The mucosal immune structure of intestine belongs to mucosa-associated lymphoid tissues, which is rich in B cells, T cells, and macrophages. Studies have shown that the epithelial lymphocytes in intestinal villi are mainly $\mathrm{T}$ cells. When the gastrointestinal mucosa is stimulated, the intraepithelial lymphocytes may migrate out of epithelium and enter lamina propria and transmit the antigenic information to the lymphocytes in the lamina propria. The sensitized T cells migrate to the extraintestinal lymphoid tissue and redistribute to the lamina propria and epithelial layer after development (Wen and Cui, 2001). In this experiment, a large number of $\mathrm{T}$ lymphocytes and macrophages show a VIP-positive reaction in the intestinal mucosa and lamina propria of pigeons, and the more the number of VIP-positive cells and nerve fibers are in the mucosal epithelium and lamina propria, the more complete the mucosal immune system is. It is suggested that VIP may be involved in the immunity of pigeon's intestinal mucosa.

\section{Function of tissue-positive nerve fibers in the intestinal wall}

The levels of VIP and its receptor 1 in mucosal crypt, submucosal layer nerve, myenteric nerve plexus of muscle increase rapidly after birth (Guo et al., 2007). In both experimental and control pigs, VIP-positive nerve fibers supply mainly ileal blood vessels, and the labeled pericarya are located in the inner and outer submucous plexus (Czaja et al., 2005). SP+ and CGRP+ nerve terminals are found in both the mucous and muscular membrane, enteric neurons are highly plastic in their response to inflammation (Czaja et al., 2005). Here, VIPpositive nerve fibers are mainly distributed in the muscular layer, which regulates the diameter of blood vessels and blood flow through vasodilatation; there is also strong VIP expression in the lamina propria of the intestinal wall, VIP is possible to influence the mucosal immune response. The widespread distribution of nerve fibers in the positive cells of pigeons suggests that its intestines may become the source of Chinese medicines that produce VIP outside the nervous system. VIP also takes on a common biological language in the neuroendocrine immune network of pigeons, which can mediate two-way information between the neuroendocrine system and the mucosal immune system. The results of RT-qPCR show that VIP expresses in different intestinal tissues of pigeon but with the highest level in the duodenum, which is the main site of digestion. It is indicated that VIP probably contribute to a significant role in regulating its digestion and immune function.

\section{ACKNOWLEDGEMENTS}

This study has been supported by the National Natural Science Foundation Project of China (No. 31960688 and 31360592) and the Natural Science Foundation Project of Jiangxi Province (20181BAB204016).

Statement of conflict of interest

The authors have declared no conflict of interest.

\section{REFERENCES}

Czaja, K., Kaleczyc, J., Sienkiewicz, W. and Lakomy, 
M., 2005. The influence of experimental ileitis on the neuropeptide coding of enteric neurons in the pig. Pol. J. Vet. Sci., 8: 155-163.

De Vadder, F., Plessier, F., Gautier-Stein, A. and Mithieux, G., 2015. Vasoactive intestinal peptide is a local mediator in a gut-brain neural axis activating intestinal gluconeogenesis. Neurogastroenterol. Motil., 27: 443-448. https://doi.org/10.1111/ nmo. 12508

Delgado, M. and Ganea, D., 2013. Vasoactive intestinal peptide: A neuropeptide with pleiotropic immune functions. Amino Acids, 45: 25-39. https://doi. org/10.1007/s00726-011-1184-8

Gao, Q., 2009. Studies on the structure of the mucosal associated lymphoid tissue and function of resist parasitism in large intestine of Bactrian camels (Camelus bactrianus) of different ages. D. Lanzhou: Gansu Agricultural University.

Gonzalez-Rey, E., Chorny, A. and Delgado, M., 2007. Regulation of immune tolerance by antiinflammatory neuropeptides. Nat. Rev. Immunol., 7: 52-63. https://doi.org/10.1038/nri1984

Guo, M.M., Huang, M.H. and Wang, C.H., 2007. Changes of vasoactive intestinal polypeptide and vasoactive intestinal polypeptide receptor 1 in small intestinal and liver during macaque development. Sheng Li Xue Bao, 59: 163-168.

Jayawardena, D., Guzman, G., Gill, R.K., Alrefai, W.A., Onyuksel, H. and Dudeja, P.K., 2017. Expression and localization of VPAC1, the major receptor of vasoactive intestinal peptide along the length of the intestine. Am. J. Physiol. Gastrointest. Liver Physiol., 313: G16-G25. https://doi.org/10.1152/ ajpgi.00081.2017

Liu, L.Q., Huo, J.F. and Yu, W.K., 1985. Studies on growth of the villus and intestinal glands of small intestine of the Jiang-qu-hai pigs. J. Jiangsu Agric. Coll., 6: 23-26.

Radfar, M.H., Asl, E.N., Seghinsara, H.R., Dehaghi, M.M. and Fathi, S., 2012. Biodiversity and prevalence of parasites of domestic pigeons (Columba livia domestica) in a selected semiarid zone of South Khorasan Iran. Trop. Anim. Hlth. Prod., 44: 225-229. https://doi.org/10.1007/ s11250-011-0002-3

Ruff, M., 1993. External and internal factors affecting the severity of avian coccidiosis. In: Proc. Sixth Int. Coccidiosis Conf., pp. 73-79.

Said, S.I. and Mutt, V., 1970. Polypeptide with broad biological activity: Isolation from small intestine. Science, 169: 1217-1218. https://doi.org/10.1126/ science.169.3951.1217
Samuelson, D.R., Welsh, D.A. and Shellito, J.E., 2015. Regulation of lung immunity and host defense by the intestinal microbiota. Front. Microbiol., 6: 1085. https://doi.org/10.3389/fmicb.2015.01085

Schwerdtfeger, L.A. and Tobet, S.A., 2020. Vasoactive intestinal peptide regulates ileal goblet cell production in mice. Physiol. Rep., 8: e14363. https://doi.org/10.14814/phy2.14363

She, R.P., Li, B.L., Liu, W. and Liu, Y.R., 2008. Immunohistochemistry and immunoelectron microscopy cytochemical localization of antibacterial peptides in sacculus rotundus and intestinal tissues of rabbit. Chinese Vet. Sci., 38: 239-243.

Tremaroli, V. and Backhed, F., 2012. Functional interactions between the gut microbiota and host metabolism. Nature, 489: 242-249. https://doi. org/10.1038/nature11552

Turner, H.L. and Turner, J.R., 2010. Good fences make good neighbors: Gastrointestinal mucosal structure. Gut Microb., 1: 22-29. https://doi.org/10.4161/ gmic.1.1.11427

Van der Zanden, E.P., Cailotto, C., Nijhuis, L., Boeckxstaens, G.E., De Jonge, W., 2010. Vagus nerve released acetylcholine can inhibit intestinal inflammation via cross talk with vasoactive intestinal peptide. Gastroenterology, 138: S-620. https://doi.org/10.1016/S0016-5085(10)62857-0

Wang, L.M., Sun, Q.S., Zhang, H., Liu, J.L., Qin, G.X. and Zhao, Y.M., 2010. Differences of tissue structure of small intestine among different varieties of beef cattle. J. Jilin Agric. Univ., 32: 326-329.

Wen, Q.Y. and Cui, Z.Z., 2001. Study on mucosal immunity of poultry. Hebei Anim. Husb. Vet. Med., 1: $15-16$.

Zhong, Y.B., Hu, X.F., Guo, H. and Li, Y., 2017. Skp2 expression exhibits a negative correlation with P27Kip1 in lungs of SD rat stress model induced by lipopolysaccharide. Indian J. Anim. Res., 51: 10191026. https://doi.org/10.18805/ijar.v0iOF.8469

Zhong, Y.B., Zhang, X.L., Lv, M.Y., Hu, X.F. and Li, Y., 2018. Detection of IL-1 $\beta$, IL-6 and TNF- $\alpha$ in Sprague-Dawely rats' atrophic thymus induced by lipopolysaccharide. Polish J. Vet. Sci., 21: 589-597.

Zhou, J.Y., Gao, C.Q., Yan, H.C. and Wang, X.Q., 2017. Research progress of heat stress on intestinal mucosal barrier function and damage repair in livestock and poultry. Feed Ind., 38: 24-29. 